\title{
"Junction" Construction of Rural Basic Education, Vocational Education and Adult Education Based on System Thinking
}

\author{
Jichuan Li \\ Elementary Education Department of Linyi University \\ Feixian County, Shandong, China \\ e-mail: dong11972@163.com
}

\begin{abstract}
Rural issues are the key problems in the comprehensive construction of a well-off society. To develop the rural education vigorously is an important factor to solve the rural issues. It is an important manifestation of the realization of educational equity to let farmers enjoy various types of education. It is an important task of rural education to achieve communication among basic education, vocational education and adult education, to build a lifelong learning "junction" and provide a lot of learning opportunities to the majority of farmers. However, it is a complex challenge to build the junction of basic education, vocational education and adult education, which needs to overall design their relationship. The system thinking theory is an important basis for solving this problem.
\end{abstract}

Keywords-system thinking; Rural basic education; Rural vocational education; Rural adult education and lifelong learning junction

\section{INTRODUCTION}

Rural issues concerning "agriculture, countryside and farmers" are prominent in China's contemporary economic and social development. How this is done is decided by the development process of modernization. Rural education is one of the key elements to solve rural issues properly. Rural development relies on talents, and talent training depends on education. Rural education determines the future of china. Therefore, it is the only way of China's rural modernization in the new century to face up the problems that the current comprehensive reform of rural education meets, vigorously reform and develop rural education, and transform the heavy population burden into an advantage of human resources.

"National Medium and Long-term Educational Reform and Development Plan (2010 2020)" has proposed to construct a complete lifelong education system, to build the "junction" of rural basic education, vocational education and adult education, and thus realize the coordinated development of academic education and non-academic education, the mutual communication between vocational education and general education, and the effective connection of pre-service education and post-service education, promote the longitudinal

Shandong Provincial Project of "12th Five -Year Plan"on Educational Science Research on the Harmony of Rural Basic Education and Vocational Education(No. 2013JG324) Stage Achievements connection and lateral communication of all forms of education at all levels, and provide multiple choices. In the current situation of rural basic education, vocational education and adult education, there are still many problems, such as educational goals being away from the actual situation of villages and farmers, the teaching contents being urbanized and exam-oriented, adult education being absent and vocational education being marginalized. Therefore, it has a vital significance to the construction of rural urbanization to mend the direction of rural education, overcome the separation of rural basic education and vocational education, integrate basic education, vocational education and adult education, achieve the coordination of basic education, vocational education and adult education, build the "junction" of rural vocational education and adult education under the new situation, and improve the overall quality of farmers.

\section{The PARAPHRASE OF THE SySTEM THINKING}

\section{A. The connotation of the system thinking}

System thinking can be traced back to system dynamics that require people to follow the basic principles in observing the world, understanding and solving problems. It enriches and improves the system methodology. Germany Cognitive Psychologist Dorner thinks "system thinking is a kind of ability that one can reason and identify things according to the circumstance". He summarized the system thinking into a refining formula: system thinking $=$ systematic and complex situation + .the full consideration on the situation. Nowadays people in the circle of international system dynamics are used to use "system thinking" to summarize the basic principle of system methodology and the system view.

System thinking is a systematic method framework to analyze, study and solve dynamic complex system problems. The core is the materialist dialectical system view. In essence, it is actually an overall dynamic thinking method to analyze and synthesize feedback information inside and outside a system with a nonlinear characteristic and an influence of time delay. It emphasizes the systems dialectical, developmental view and the mutual interacting and continuous development relationship among each part of the system and the system and the en- 
vironment. It allows us to see the correlation rather than a single event, and gradual changes of form rather than a fleeting scene. In other word, it is a dynamic developmental situation rather than static snapshots in front of people.

\section{B. The basic views of system thinking}

At present, there are four basic points of authorized system thinking.

- Causal thinking. The foundation of this kind of thinking is the strict description of cause and effect. In order to explain a phenomenon, we have to find its "cause". Assuming that these causes exist, we can observe the corresponding effects as long as causes are valid at all times. In fact, some words, such as "because", "so", "assumed", have expressed these thoughts in our daily life. In accordance with the mathematical analogy, it is the function concept of the independent variable (= "cause") and dependent variable (= "effect"). Therefore, compared with causal thinking, the thinking of simple relationship of cause and effect can only be called function thinking or linear thinking. In causal thinking, we should consider indirect result, mutual influence of cause and effect, the feedback loop; these structures develop and change with time. We need to have a dynamic viewpoint for correctly understanding of the feedback loop, so that we can see events clearly over time.

- Dynamic thinking. A system influenced by the passage of time has a certain behavior. Time delay and swing are the typical characteristics of the system. We can not observe the swing of the system with no time span. Even the simple constant temperature experiment in the simulation air-conditioning room is a very difficult task to many disciplines, because the temperature change takes time. Every time it needs a period of time to raise or reduce temperature. If we do not consider the time, it is likely to lead to a radical reaction that throws the system out of control. In real life people will not do so. But in other systems, people do not fully understand this. Dynamic thinking also means foreseeing (possible) development and changes in the future. For the actual operation of the system, it is not enough to rely on the review of past development. The simulation model is very helpful or even necessary to predict the development of system in the future - especially when the real situation goes slowly.

- Model thinking. System thinking requires us to correctly handle our awareness and understanding on reality, rather than the reality itself. In other word, it needs us to correctly understand the model constructed according to the reality. We usually can only think based on our description of reality and impression on reality. The model is our reaction to the reality. To think in the model can help us understand the reality better (or profoundly). To think in the model in fact also implies an ability to build a model. After the model is built, we must verify the effectiveness of the model, and further expand it. The construction of a model and the probability of success of model analysis are largely dependent on the description tool of the model. For system thinking, it is essential to choose an appropriate way of expression.

- Control system. This is the fourth basic point of the system thinking. We can also call it driving system. System thinking cares about the expected behavior of the system as well as our doings to the system. The most basic and important issue to the management of the practical system is that "what structural component will directly result in a change of certain behavior of the system?" In the social system, it usually is impossible to directly change the behavior of others. A person can only change his/her own behaviors. In economic system, manufacturers usually cannot control the market directly; market activity usually is supplier's behavior in order to arouse demand desire of demander.

\section{StRATEGY OF "JUnCTION" CONSTRUCTION OF RURAL BASIC EDUCATION, VOCATIONAL EDUCATION AND ADULT EDUCATION BASED ON THE SYSTEM THINKING}

\section{A. To complete the overall construction of "credit system" of all levels and types of educations and education forms and to establish the credit bank}

"Credit" is a unit used as a measure of work completed by students and credit system is a teaching management system which is opposite to the academic year system and uses the minimum total credits required to graduate as a measure of work completed by students and a standard for graduation, including academic credit system, complete credit system, grade point credit system, weighted credit system and additional credit system. Credit system allows students to make their own academic arrangement based on their abilities and interests or even to change their majors at any time, which truly realizes "choose what I love, love what I choose", motivates learning enthusiasm, initiative and independence and effectively develops students' potential. Credit bank, notable as an advanced pattern of credit system, is the best form to complete the overall construction of credit system. Credit bank system (CBS, for short), originating in South Korea, refers to a credit management mode where credits are earned by learners through taking courses at a school or a training institution designated by the state or taking a nationally-recognized credit certification examination, and then are stored in an individual account registered in credit management system, and learners are qualified for diploma and degree certificate of higher education when their accumulative credits meet the required number. Although credit bank has a function of storage and exchange with reference to the basic mechanism of a bank, it is used for storage of credit and exchange for appropriate diploma and qualification certificate. It realizes the installment fixed deposits for credit, breaks down the barrier to all types and forms of educations, integrates a variety of educational resources and meets the sharing of educational resources, so it is an ideal way to real- 
ize lifelong learning, lifelong education and the establishment of a learning-oriented society.

From the perspective of system thinking, credit system bank is a complicated systematic project, and its operational procedures shall be designed as a whole. At present, our country does not have mature operational procedures of a credit bank, and a majority of researchers tend to develop the operational procedures of a credit bank with reference to the operational procedures of credit system management of self-taught examination in China.

Specifically: to establish a specialized credit certification authority as a head office of provincial credit bank relying on the education and examination institutes at provincial (city, autonomous region and municipality) level, to build a municipal subsidiary bank in self-taught examination offices or admission offices in various cities, and to set up county-level branches in admission offices at county and district levels. The credit bank is applied for student registration, credit certification, review, approval and issuance of credit check list, and students will be awarded appropriate diploma and qualification certificates in response to the application they have made if they are qualified upon the review by experts and approval by the license-issuing authority. The credit bank integrates different types and forms of education and realizes the mutual recognition of credits, mutual recognition between diploma and qualification certification, so it is an important way to complete the junction construction of rural basic education, vocational education and adult education and then to realize the desired rural basic education, vocational education and adult education.

\section{B. To complete the overall design of all levels and types of} academic education and then to realize the

communication and convergence of academic education after junior high school

The principle of thinking system suggests that academic education after junior high school constitutes the entire academic education in China, and various forms of education are in interdependence and inter-premise and work together to form an academic education system. The academic education after junior high school should be designed as a whole for its best results, so that a variety of academic education can be effectively converged to support the junction construction of rural basic education, vocational education and adult education.

1)The realization of effective convergence between basic education and higher education.

Basic education and higher education are two important stages of the entire education system which are relatively independent of each other and interactive with each other, on the one hand, basic education is the foundation of higher education, so whether it is desirable has a significant effect on higher education in every respect; on the other hand, higher education plays a considerable role in guiding the enrollment model, curriculum arrangement, educational philosophy and teaching management of basic education. Thus, for many problems in basic education and higher education, we should not unilater- ally seek solutions from the inside, but comprehensively research higher education and basic education as a system and think about the problems from a perspective of convergence. In order to enhance the convergence between higher education and basic education, we can start from at least four (five?) aspects below: firstly, to reform the college admission system, to implement classified examination, comprehensive evaluation and multiple admission, to establish a multidimensional reference for higher education enrollment; secondly, to build a platform for communication to facilitate the convergence and interaction between higher education and basic education; thirdly, to innovate the teaching content and to reconstruct the curriculum system for forming a progressive relation between basic education and higher education in teaching content and establishing a interrelated curriculum system; fourthly, to carry out special link-up education for higher education and basic education respectively; fifthly, to unify the educational philosophy of higher education and basic education, to abandon the concept of exam-oriented education in basic education and to correctly position competence-oriented education of higher education.

2)Realization of effective convergence between the secondary vocational education and higher vocational education.

Vocational education is a characteristic education developed to train students' vocational skills and an important integral part of the Chinese education system. We should establish a perfect vocational education system, improve the mutual convergence of basic, secondary and higher vocational educations and realize the convergence and communication between secondary vocational education and higher vocational education. We should focus on the following: the first one is the convergence and communication of educational objectives of secondary vocational education and higher vocational education; the second one is the convergence and communication of teaching system and academic structure of secondary vocational education and higher vocational education; the third one is the optimization of majors, reform of curriculum reform and development of teaching materials for the realization of convergence and communication of secondary vocational education and higher vocational education; the last one is to train high-quality teaching staff for vocational education and then to realize the communication and convergence between secondary vocational education and higher vocational education.

3)Realization of effective convergence between continuing education and vocational education.

Continuing education is an integral part of the Chinese education system and an important link for establishment of system of rural basic education, vocational education and adult education. The communication and convergence between continuing education and vocational education is an effective way to promote the construction of a learning-oriented society, the creation of lifelong education system and the junction construction of rural basic education, vocational education and adult education. For this reason, we should start with four as- 
pects below: firstly, to change the original educational system, to enhance the educational policy guidance for the realization of integration of education system, to encourage the extension of vocational education to higher vocational education, to create conditions to facilitate graduates in further education as to realize the lifelong vocational education and develop vocational education into lifelong education from terminal education, and the convergence between continuing education and vocational education is a good form to put this idea into practice; secondly, to highlight professionalism, practicability and fundamentality to realize the convergence of training purposes of secondary vocational education and continuing education. Thirdly, based on the development tendency and market demand of education in the world, to broaden the inclusiveness of majors, to enhance the adaptability of majors, to strengthen the construction of specialized vocational education with support of local government and industries, to study and work out a major catalog for secondary vocational education and continuing education in order to converge the majors of these two levels of educations better and then to realize the convergence of major arrangement. The fourth one lies in the implementation of standardized curriculum. Curriculum should be arranged based on the principles of innovation, adaptability and practicality; vocational education should be characterized by the practicality and ability training and suitable for the national occupational classification, vocational qualification system and employment system from the perspective of regional economic development and social needs, and we should focus on scientific research, curriculum design, curriculum system innovation in order to improve students' professional quality and employability to realize the convergence of curriculum of secondary vocational education and continuing education.

\section{CONCLUSION}

We can achieve the connection of all types of education and all forms of education, and the mutual recognition and conversion of all kinds of education fruits by using system thinking theory to guide the "junction" construction of rural basic education, vocational education and adult education, thinking and looking at all types of education and all forms of education from the overall view of the construction of a learning-oriented society, putting them into the unified system of rural basic education, vocational education and adult education, and interacting and interrelating internal elements of the system, the element and the system.

\section{REFERENCES}

[1] Xinjun Zhu. 2011. The idea, path and countermeasures of the construction of learning-oriented society. Modern Distance Education Research, (1).

[2] Jichuan Lee. 2011. The "Junction" construction of lifelong learning based on system thinking. Chinese Vocational \& Technical Education (27).

[3] Bing Qin \& Rong Hu. 2009. Analysis on credit bank system of higher education in South Korea. Comparative Education Research (12).
[4] Peng Ding. 2011.Credit Bank: foundation of the construction of further education junction. Journal of Adult Education College of Hubei University (1).

[5] Hongyi Jin \& Lihong Wang. 2009. Study on the connection of the vocational education and vocational qualification certificate system. Further Education Research (7). 